\title{
Tylosaurus kansasensis, a new species of tylosaurine (Squamata, Mosasauridae) from the Niobrara Chalk of western Kansas, USA
}

\section{M.J. Everhart}

Sternberg Museum of Natural History, Fort Hays State University, Hays, Kansas 67601, USA. Email: meverhar@fhsu.edu

Manuscript received: December 2004; accepted: January 2005

\begin{abstract}
Tylosaurus kansasensis sp. nov. is described herein on the basis of thirteen specimens collected from the Smoky Hill Chalk (upper Coniacian) of western Kansas, USA. The new species, originally designated Tylosaurus n. sp., co-occurred with T. nepaeolicus and exhibits a number of primitive characters that place it in a basal position in the mosasaur phylogeny. Among the key differences separating this species from other tylosaurines are a shortened, more rounded pre-dental process of the premaxilla, a distinctive quadrate lacking an infrastapedial process, and a parietal foramen located adjacent to the frontal-parietal suture.
\end{abstract}

Keywords: Cretaceous, Niobrara, mosasaur, Tylosaurus kansasensis, Western Interior Sea, new species

\section{Introduction}

Mosasaurs (Squamata, Mosasauridae) are extinct marine lizards that flourished worldwide during the last 25 million years of the Cretaceous. Mosasaur remains are preserved in marine sediments of middle Turonian through late Maastrichtian age, and are especially abundant and well preserved in the Smoky Hill Chalk Member (upper Coniacian - lower Campanian) of the Niobrara Chalk in western Kansas (USA).

Tylosaurs are among the earliest known mosasaurs from the Western Interior Sea of North America. One of the largest mosasaur species, Tylosaurus proriger, was first described from the upper Smoky Hill Chalk (early Campanian) by Cope (1869). The remains of tylosaurine mosasaurs have also been collected from Europe, Japan, New Zealand and Antarctica. Remains of a second, earlier tylosaurine species, Tylosaurus nepaeolicus, occur in the lower Smoky Hill Chalk (upper Coniacian) along with those of Platecarpus tympaniticus and Clidastes liodontus.

The type specimen of Tylosaurus proriger (MCZ 4374) was discovered near Monument Rocks in Gove County, and was obtained by Professor Louis Agassiz during his 1868 visit to western Kansas (Cope, 1869; Williston, 1898; Russell, 1967). It was the first mosasaur to be described from Kansas and was originally named 'Macrosaurus' proriger by Cope. The description of the new species by Cope (1869) in the minutes of the June 1 meeting of the Academy of Natural Sciences of Philadelphia is brief by modern standards, 'He made some remarks on a fine fragment of the muzzle of a large Mosasauroid, which pertained to a cranium of near five feet in length. The pterygoid bones were separated from each other, and support nine teeth. A peculiarity of physiognomy was produced by the cylindric prolongation of the premaxillary bone beyond the teeth, and a similar flat prolongation of the extremity of the dentary. He referred the species to Macrosaurus 0wen, under the name M. proriger.'

The following year, Cope $(1870$, pl. 12, figs 22, 23) described the same specimen more completely, figured it and, with little explanation, referred it to another European genus, Liodon Owen. Marsh (1872a, p. 461), apparently recognising significant differences between American and European mosasaurs, proposed a new genus ('Rhinosaurus', nose lizard) from a more complete specimen (YPM 1268) he had collected 'on the south side of the Smoky Hill River' in 1871. However, that name was preoccupied and Cope (1872, p. 141) proposed the genus name Rhamphosaurus. In a brief note, Marsh (1872b, p. 147) wrote 
that, 'as this name (Rhinosaurus) proves to be preoccupied, it may be replaced with Tylosaurus. The name Rhamphosaurus, since suggested by Prof. Cope, cannot be retained, as it was given to a genus of lizards in 1843 by Fitzinger.' Leidy (1873, p. 274) was the first to place 'Macrosaurus' proriger Cope, 1869 into Tylosaurus Marsh.

As an example of the early skirmishes ('Bone Wars') between Cope and Marsh over the naming of newly discovered fossils, Cope $(1874,1875)$ apparently ignored Marsh's revision, and named a second Tylosaurus species 'Liodon' nepaeolicus (AMNH 1565) from remains discovered by B.F. Mudge in the lower Smoky Hill Chalk along the Solomon (Nepaholla) River (Everhart, 2002). The genus name went unchallenged until Merriam (1894, p. 24) placed 'Liodon' nepaeolicus Cope, 1874 into Tylosaurus. Regarding Cope's description, Williston (1898, p. 176) wrote that, 'the characters given - such as may be valid - are altogether too slight to distinguish the species, and I do not think that T. nepæolicus is entitled to recognition.' Since that time, the second species has been included in work by Russell (1967), Schumacher (1993), Sheldon (1996), Bell (1993, 1997) and Everhart (2002), and is considered here to be valid on the basis of more complete specimens discovered since Williston's time. However, Everhart (2002) noted that besides the differences in time of occurrence of $T$. nepaeolicus and T. proriger, only minor morphological features (and the larger size of $T$. proriger) appear to separate the two species. Whether or not T. nepaeolicus and T. proriger represent a single chronospecies is a question that requires further study.

Russell (1967), Schumacher (1993) and Sheldon (1996) reported that $T$. nepaeolicus is found in the lower chalk (upper Coniacian - lower Santonian), while T. proriger is known only from the upper chalk. In their review of museum collections, neither Schumacher (1993) nor Sheldon (1996) reported specimens of $T$. proriger from below the upper Santonian. The earliest known remains of T. proriger (FFHM 1997-10) were described by Everhart \& Everhart (1997) from the middle Santonian chalk of Gove County. In his revision of mosasaur biostratigraphy of the Smoky Hill Chalk, Everhart (2001) noted that T. nepaeolicus was present in the upper Coniacian and lower Santonian chalk in Kansas.

While it is possible that Cope $(1875$, pl. 28, figs 8,9$)$ may have figured the distinctive, abbreviated premaxilla of the third species as that of 'Liodon dyspelor', Stewart (1990) was the first to document the existence of Tylosaurus n. sp. An examination of the extensive 1870s collection from Kansas in the Yale Peabody Museum by Bell (1993) determined that a specimen of the third species (YPM 40796) had been collected in 1876, but was then identified no further than Tylosaurus sp. The characteristics of an 'undescribed' species of Tylosaurus were discussed by Schumacher (1993) in regard to specimens in the collection of the Sternberg Museum (FHSM VP-78, VP-2295 and VP-3366), and a list of diagnostic characters (Table 1) was compiled by Bell (1993). The undescribed species was included in a phylogenetic analysis of the Mosasauroidea by Bell (1993, 1997) where it was placed as the basal member of the Tylosaurine in his informal subfamily 'Russellosaurinae'.

Thirteen specimens of Tylosaurus kansasensis sp. nov. (Table 2) are here reported from the collections of five museums. Nine of these specimens, including the holotype and one paratype, are curated in the Sternberg Museum of Natural History, Fort Hays State University, Hays, Kansas. As near as can be determined, all of the Kansas specimens documented in this report are from the lower one-third (upper Coniacian) of the Smoky Hill Chalk Member of the Niobrara Chalk (Appendix 1).

Table 1. Characters of Tylosaurus kansasensis sp. nov. (adapted from Bell, 1993).

1. Premaxilla rostral foramina large

2. Infrastapedial process of quadrate greatly reduced or absent

3. Medial ridge of quadrate diverges ventrally

4. Keel on dorsal midline of frontal high, thin and well developed

5. Medial sutural flanges from frontal extend long distance onto parietal

6. Parietal foramen adjacent to or invades fronto-parietal suture

7. Dorsal postorbitalfrontal with low rounded transverse ridge

8. Posteroventral angle of jugal virtually 90 degrees

9. Ectopterygoid does not contact maxilla

10. Quadrate suprastapedial process without constriction

11. Quadrate ala thick

12. Alar concavity of quadrate shallow

13. Radius slightly expanded

\section{Abbreviations}

AMNH - American Museum of Natural History, New York, NY; FHSM - Fort Hays State University, Sternberg Museum of Natural History, Hays, Kansas; FGM - Fryxell Geology Museum, Augustana College, Rock Island, Illinois; LACMNH - Los Angeles County Museum of Natural History, Los Angeles, CA; MCZ - Museum of Comparative Zoology, Harvard University, Cambridge, MA; TMM - Texas Memorial Museum, University of Texas at Austin, TX; YPM - Peabody Museum of Natural History, Yale University, New Haven, CT.

\section{Systematic palaeontology}

Order Squamata

Family Mosasauridae

Genus Tylosaurus Marsh, 1872b

\section{Tylosaurus kansasensis sp. nov., Figs 1 - 9}

Material - Holotype is FHSM VP-2295, a complete, articulated skull and seven cervical vertebrae, preserved in dorsal/left 
Tab. 2. Currently identified specimens of Tylosaurus kansasensis sp. nov. (compiled from Bell, 1993, 1997, pers. comm. 2005; Schumacher, 1993; present paper).

\begin{tabular}{|c|c|c|c|c|c|}
\hline $\begin{array}{l}\text { Specimen } \\
\text { number }\end{array}$ & $\begin{array}{l}\text { Location of } \\
\text { parietal foramen }\end{array}$ & $\begin{array}{l}\text { Infrastapedial } \\
\text { present/absent }\end{array}$ & $\begin{array}{l}\text { Premaxilla } \\
\text { shape }\end{array}$ & $\begin{array}{l}\text { Pre-dental } \\
\text { process length }\end{array}$ & $\begin{array}{l}\text { Lower } \\
\text { jaw length }\end{array}$ \\
\hline FHSM VP-2295* & near suture & absent & rounded & $2.0 \mathrm{~cm}$ & $72 \mathrm{~cm}$ \\
\hline FHSM VP-78 & near suture & absent & rounded & $\mathrm{n} / \mathrm{a}$ & $45 \mathrm{~cm}$ \\
\hline FHSM VP-2495** & near suture & absent & $\mathrm{n} / \mathrm{a}$ & $\mathrm{n} / \mathrm{a}$ & $50 \mathrm{~cm}$ \\
\hline FHSM VP-3366 & $\mathrm{n} / \mathrm{a}$ & absent & rounded & $2.3 \mathrm{~cm}$ & $\mathrm{n} / \mathrm{a}$ \\
\hline FHSM VP-9350 & $\mathrm{n} / \mathrm{a}$ & absent & rounded & $1.0 \mathrm{~cm}$ & $37.0 \mathrm{~cm}$ \\
\hline FHSM VP-13742 & $\mathrm{n} / \mathrm{a}$ & $\mathrm{n} / \mathrm{a}$ & rounded & $2.4 \mathrm{~cm}$ & $98.0 \mathrm{~cm}$ \\
\hline FHSM VP-14848 & $\mathrm{n} / \mathrm{a}$ & absent & $\mathrm{n} / \mathrm{a}$ & $\mathrm{n} / \mathrm{a}$ & $\mathrm{n} / \mathrm{a}$ \\
\hline FHSM VP-15631 & near suture & $\mathrm{n} / \mathrm{a}$ & rounded & $2.2 \mathrm{~cm}$ & $76.0 \mathrm{~cm}$ \\
\hline FHSM VP-15632 & near suture & absent & rounded & $1.1 \mathrm{~cm}$ & $42.0 \mathrm{~cm}$ \\
\hline FGM V-43 & $\mathrm{n} / \mathrm{a}$ & absent & rounded & $2.5 \mathrm{~cm}$ & $82.5 \mathrm{~cm}$ \\
\hline MCZ 1589 & $\mathrm{n} / \mathrm{a}$ & absent & rounded & $2.0 \mathrm{~cm}$ & $80.9 \mathrm{~cm}$ (est.) \\
\hline YPM 40796 & near suture & absent & $\mathrm{n} / \mathrm{a}$ & $\mathrm{n} / \mathrm{a}$ & $43.0 \mathrm{~cm}$ (est.) \\
\hline LACMNH $127815^{* *}$ & near suture & absent & rounded & $n / a$ & $73.0 \mathrm{~cm}$ (est.) \\
\hline TMM 40092-27 & $\mathrm{n} / \mathrm{a} \quad \mathrm{n} / \mathrm{a}$ & rounded & $\mathrm{n} / \mathrm{a}$ & & \\
\hline TMM 81051-64 & $\mathrm{n} / \mathrm{a} \quad$ absent & rounded & $\mathrm{n} / \mathrm{a}$ & & \\
\hline
\end{tabular}

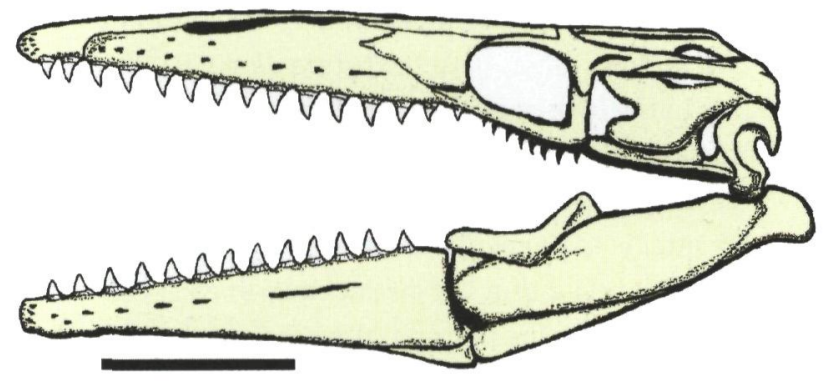

Fig. 1. Skull of Tylosaurus kansasensis $s p$. nov. in left lateral view, based on the holotype (FHSM VP-2295). Scale bar equals $15 \mathrm{~cm}$; adapted from a drawing of T. nepaeolicus by Russell (1967, fig. 95).

lateral view (Fig. 2). The specimen was collected from the lower Smoky Hill Chalk Member (Niobrara Chalk) in Ellis County by M.V. Walker and others in November, 1968, '8 miles northeast of Ellis, Kansas.' Paratypes: LACMNH 127815 and FHSM VP-2495 (Appendix 1). Other referred specimens: FHSM VP-78, VP-3366, VP-9350, VP-13742, VP-14848, VP-15631, VP-15632, FGM V-43, MCZ 1589 and YPM 40796 (Appendix 1).

Etymology - Named for the Kaw Indians, an American Indian tribe also known as the Kanza, from which the name of the state (Kansas) is derived and where all of the known specimens have been collected.

Stratigraphic occurrence - While the exact locality and stratigraphy of specimens of Tylosaurus kansasensis sp. nov. collected prior to 1968 are generally unknown, all remains found since that time, including those of the type specimen, were discovered in the lower Smoky Hill Chalk, and are of late
Coniacian age. This stratigraphic interval includes Hattin's (1982) marker units (mu) 1-5, and Stewart's (1990) biostratigraphic zones of Protosphyraena perniciosa and Spinaptychus n. sp.

Description - Bell (1993) listed thirteen characters that separate Tylosaurus kansasensis sp. nov. from T. proriger and T. nepaeolicus (Table 1). More recently, Bell (pers. comm., 2004) indicated that some of these characters are 'artifacts of PAUP analysis, and may or may not apply to $T$. kansasensis.' The most often preserved and readily recognisable of these features include the abbreviated pre-dental process of the premaxilla, a distinctive quadrate lacking an infrastapedial process, and

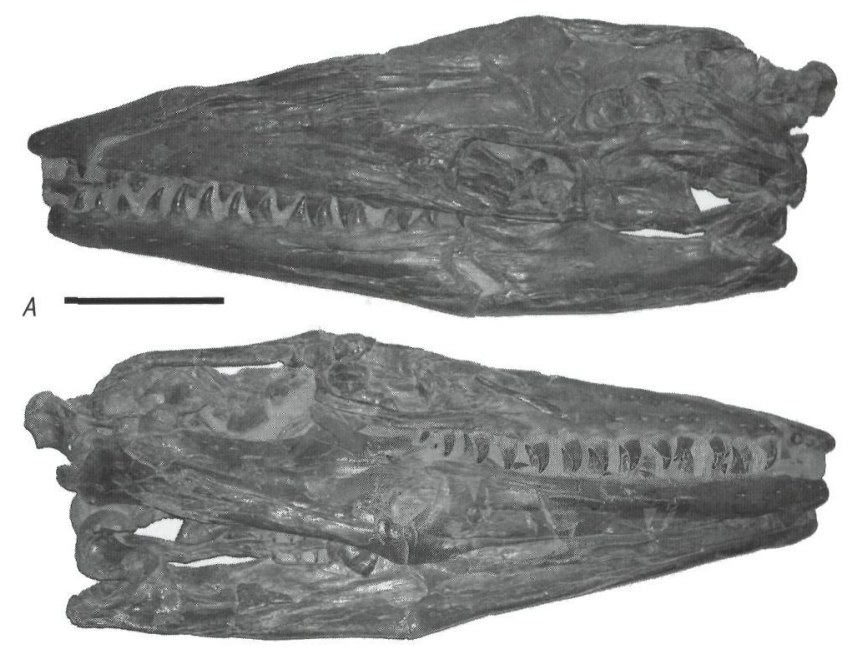

Fig. 2. Skull of Tylosaurus kansasensis sp. nov. (FHSM VP-2295, holotype); $A$ - in left dorsal-lateral view; $B$ - in right ventral-lateral view. Scale bar equals $15 \mathrm{~cm}$. 
the location of the parietal foramen adjacent to or invading the suture between the parietal and frontal. The pre-dental process of the premaxilla is shorter and more rounded compared to that of $T$. nepaeolicus and T. proriger, and typically exhibits larger rostral foramina. The length of pre-dental process averaged $2.7 \%$ (range $=2.5-3.0 \%$ ) of the length of the lower jaw for seven specimens of T. kansasensis sp. nov. (Table 2) compared with $4.8 \%$ for three specimens of $T$. proriger and $4.2 \%$ for a single specimen of $T$. nepaeolicus.

The quadrates of Tylosaurus kansasensis sp. nov. are typically wider laterally relative to their height than those of the other two species. As noted by Bell (1993), the infrastapedial process is poorly developed or absent, the medial ridge of the quadrate diverges ventrally, the suprastapedial process is not constricted, the ala is thick, and the alar cavity is shallow (Fig. 3). The stapedial pit is relatively large, lozenge shaped, and about twice as long as it is wide.

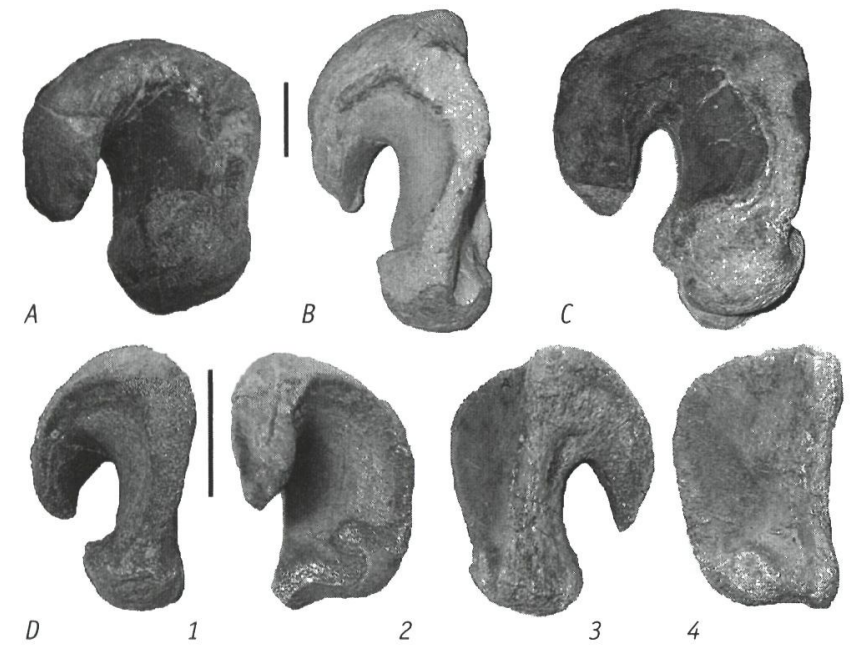

Fig. 3. The right quadrates of three adult specimens of Tylosaurus kansasensis sp. nov.; A - FHSM VP-2295 (holotype); B - FHSM VP 3366; $C$ - FGM V-43, in lateral view. Scale bar equals $2 \mathrm{~cm} ; D$ - right quadrate of a juvenile T. kansasensis sp. nov. (FHSM VP-15632) in lateral, posterior, medial and anterior view, respectively. Scale bar equals $2 \mathrm{~cm}$.

Williston (1898, p. 118) noted that in the genus Tylosaurus, 'the pineal (parietal) foramen is rather small, and is usually enclosed in the parietal, though it may border the anterior suture.' However, Williston did not designate or figure a specimen with a parietal foramen bordering on the suture between the parietal and the frontal. Because Williston (1898, p. 88) also believed that Tylosaurus ranged from the lower part of the Niobrara (uppermost Turonian-lower Coniacian), he may have been describing the condition present in $T$. kansasensis sp. nov. Although crushing has distorted and partially closed the parietal foramen in the type specimen of $T$. kansasensis $\mathrm{sp}$. nov. (FHSM VP-2295), the opening is readily visible just posterior to the suture between the parietal and the frontal (Fig. 4). The parietal foramen is located near the anterior edge of the

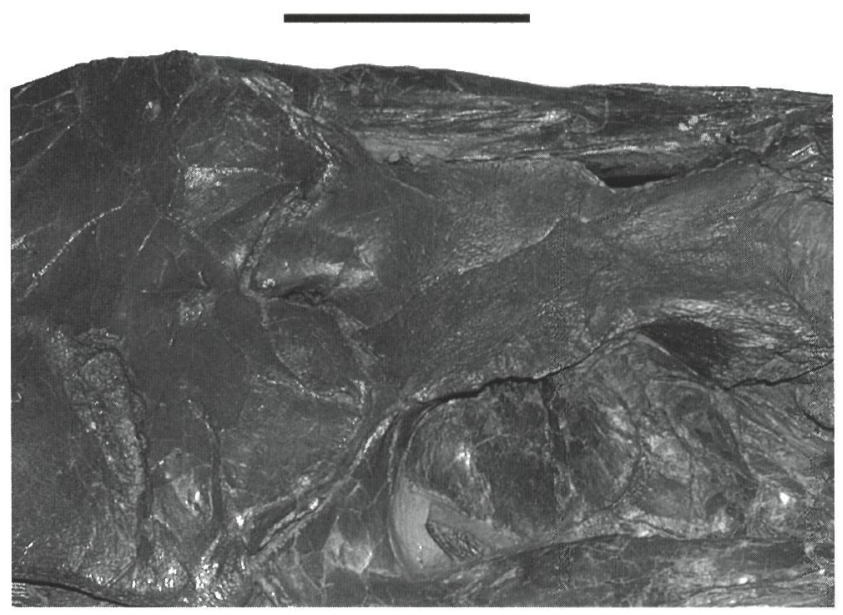

Fig. 4. Dorsal view of the contact between the frontal and parietal of the holotype of Tylosaurus kansasensis sp. nov. (FHSM VP-2295). Note the large, unhealed bite mark on the frontal at lower left. Scale bar equals $2 \mathrm{~cm}$.

parietal in these specimens; FHSM VP-78, VP-2495 (Fig. 5), VP15631, and VP-15632, but is obscured by the plaster mounting of FGM V-43. The anterior location of the parietal foramen is a major distinguishing feature between the new species and co-occurring T. nepaeolicus where it is located 3 - 4 diameters posterior to the frontal-parietal suture (Russell, 1967, textfig. 93A). In the later occurring $T$. proriger, the parietal foramen is located about 1 diameter posterior to the suture (Williston, 1898, pl. XVII).

The frontal is triangular in dorsal view, with slightly sigmoid lateral margins and a thin but distinct mid-line keel anteriorly. The anterior wing of the postorbital-frontal abuts the posterior extension of the prefrontal and excludes the lateral edge of the frontal from the orbit (Fig. 6A). The nares open just

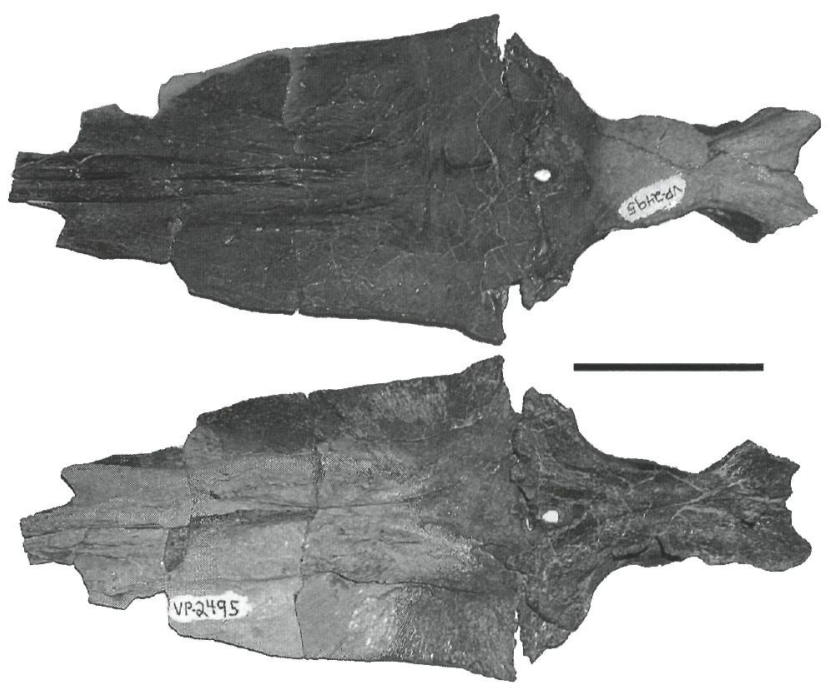

Fig. 5. Dorsal and ventral views of the frontal and parietal of a juvenile Tylosaurus kansasensis sp. nov. (FHSM VP-2495), showing the location of the parietal foramen adjacent to the frontal-parietal suture. Scale bar equals $5 \mathrm{~cm}$. 


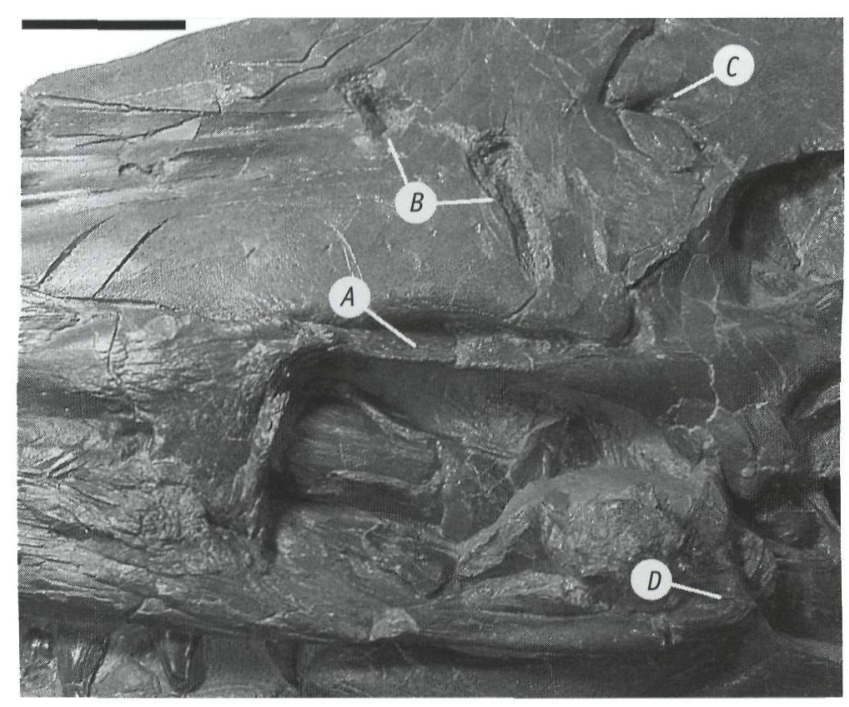

Fig. 6. A dorsal/left lateral view of the mid-skull of Tylosaurus kansasensis sp. nov. (FHSM VP-2295; holotype): A - the prefrontal abuts the postorbitalfrontal and excludes the frontal from the orbit; $B$ - two unhealed bite marks on the frontal; $C$ - the parietal foramen; $D$ - the right angle formed by the ventral and posterior wings of the jugal. Scale bar equals $3 \mathrm{~cm}$.

anterior to or over the fourth tooth of the maxilla, similar to T. nepaeolicus, and an early (middle Santonian) specimen of T. proriger (FFHM 1997-10) reported by Everhart \& Everhart (1997). In contrast, the nares are located behind the fifth tooth of the maxilla in the type of T. proriger (MCZ 4374), the complete skull of the exhibit specimen in the Sternberg Museum (FHSM VP-3) and other specimens of this species from the upper (Campanian) chalk. The internarial bar is broadly triangular in cross section in LACM127815 and FHSM VP-15632 as opposed to the subrectangular shape observed in T. nepaeolicus and T. proriger (Bell, pers. comm., 2005). In FGM V-43 the slightly damaged sclerotic ring (Fig. 7) is composed

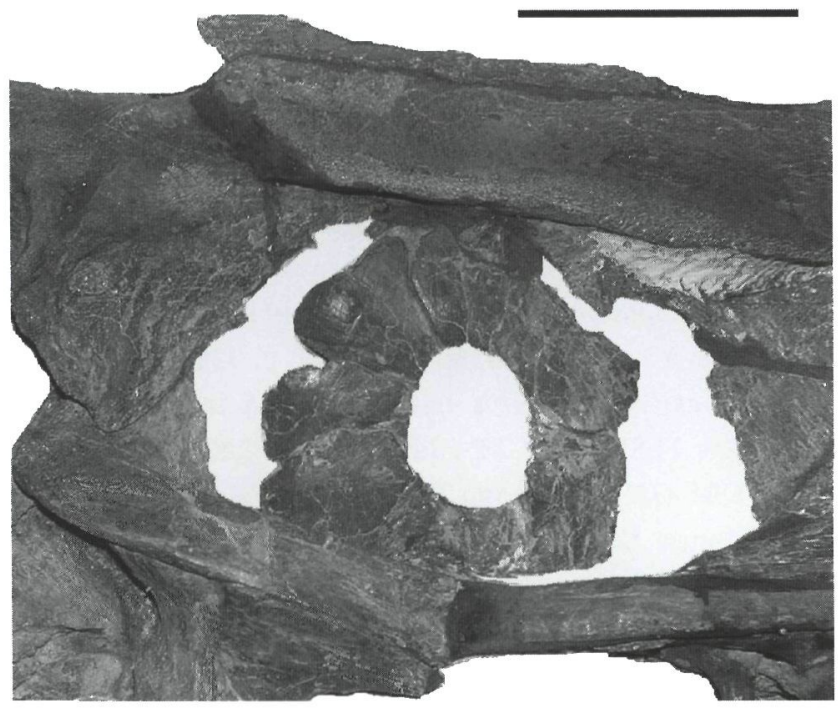

Fig. 7. The sclerotic ring in the right orbit of Tylosaurus kansasensis $s p$. nov. (FGM V-43) in right lateral view. Scale bar equals $5 \mathrm{~cm}$. of at least twelve plates, supporting Russell's (1967, p. 58) suggestion that 'about 14 such plates are present in mosasaurs'. As noted by Bell (1993; Table 1), the posterior and ventral portions of the jugal form a nearly 90 degree angle in Tylosaurus kansasensis sp. nov. (Fig. 6D).

The dentary represents about $56-58 \%$ of the length of the lower jaw, similar to that of T. proriger and T. nepaeolicus (Everhart, 2002). Also, like the other species of Tylosaurus, the edentulous tip of the lower jaw extends anteriorly beyond the first tooth and is rectangular in lateral view (Russell, 1967, p. 50). Tooth counts are similar to T. nepaeolicus and T. proriger with twelve-thirteen teeth in the maxilla, thirteen in the dentary, and ten-eleven in the pterygoid. The teeth are cone shaped, round in cross-sectional view and slightly recurved. They are not facetted, but do have weak striations and poorly developed carinae that are not serrated. The teeth do not exhibit any features that would readily distinguish them from those of either T. proriger or T. nepaeolicus.

With the exception of LACMNH 127815 and FHSM VP-15631, post-cranial material is limited, consisting mainly of cervical and dorsal vertebrae. Bell (pers. comm., 2005) noted that rudimentary zygosphenes and zygantra are present on the axis through the 5th cervical vertebra of the paratype (LACMNH 127815), a character not found in other members of the genus. Limb bones are infrequently recovered in association with mosasaur specimens from the Smoky Hill Chalk due to postmortem scavenging by large sharks (Everhart, 2004). Bell (1993) noted that the radius is slightly expanded in LACMNH 127815 compared to T. proriger and T. nepaeolicus. Most of the front limbs, including both radii, are present in FHSM VP-15631 but are too damaged by weathering for accurate comparison. No other significant differences are noted between $T$. kansasensis sp. nov. and other tylosaurines, and the reader is referred to Russell (1967) for a general description of the post-cranial characteristics of tylosaurines.

In the holotype (FHSM VP-2295), the midline length of the skull (premaxilla to occipital condyle) is $65 \mathrm{~cm}$ and the lower jaws measure $72 \mathrm{~cm}$. The nares open posterior to a line drawn between the 3rd and 4th teeth of the maxillae, approximately $8 \mathrm{~cm}$ behind the suture of the premaxilla and the maxillae. Both quadrates are preserved in lateral view on the 'underside' of the specimen, and are $7.5 \mathrm{~cm}$ (right) and $8.0 \mathrm{~cm}$ (left) in height. The remains preserve two large gouges across the frontal, other puncture wounds to the dorsal and left side of the skull, and additional damage to the right dentary that are interpreted here as unhealed bite marks (see also Schumacher, 1993). It is most likely that the injuries are evidence of a fatal encounter with a larger mosasaur.

Tylosaurus kansasensis sp. nov. was included (as Tylosaurus novum sp.) within the phylogenetic revision of the Mosasauroidea by Bell $(1993,1997)$, using the characters of the holotype (FHSM VP-2295) and one of the paratypes (LACMNH 127815). Bell (1993, 1997) concluded that 
Tylosaurus novum sp. was the most basal species of the genus Tylosaurus. Although seven additional specimens have been identified since 1997, no new information has been added to the data base that would change the original diagnosis, and it is not repeated here.

\section{Discussion}

Tylosaurus kansasensis sp. nov. is a relatively derived, moderately-sized tylosaurine mosasaur (adult length about $7 \mathrm{~m}$ ) occurring in the Niobrara Chalk (upper Coniacian) of the Western Interior Sea (North America). It is represented here by thirteen specimens collected between 1876 and 1990 from the Smoky Hill Chalk Member in western Kansas. The new species co-occurred with Clidastes liodontus, Platecarpus tympaniticus and T. nepaeolicus, with all of which it has been occasionally misidentified. In some part, the confusion and lack of formal recognition for more than a century since the first specimens were collected has been due to its overall appearance being similar to several previously recognised species.

In 1979, the remains of an adult Tylosaurus (FHSM VP-15631) consisting of a nearly complete skull, 42 articulated cervical, dorsal, pygal and caudal vertebrae, ribs and front limbs were collected by the author from near the base of the Smoky Hill Chalk (upper Coniacian). It was noted to have an unusually short pre-dental rostrum on the premaxilla (Fig. 8A, B), and a parietal foramen that opens anteriorly on the frontal-parietal suture. As complete as the remains were, they were damaged by subsurface weathering and could not be positively identified at the time as either of the known species of Tylosaurus.

In his discussion of the biostratigraphic zone of Protosphyraena perniciosa in the Smoky Hill Chalk, Stewart
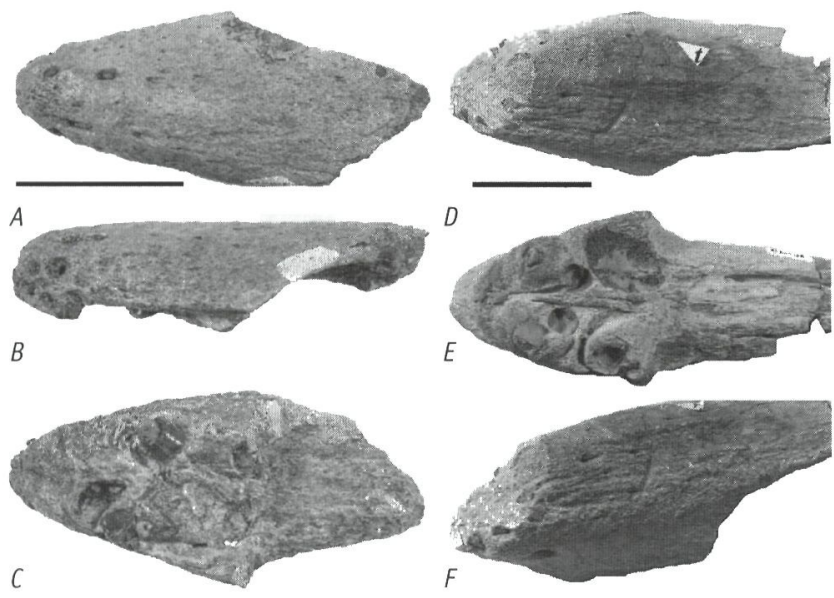

C

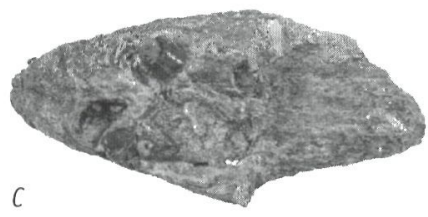

F

Fig. 8. Left: the premaxilla of an adult Tylosaurus kansasensis sp. nov. (FHSM VP-15631) in ventral (A), left lateral (B) and dorsal (C) view; right: the premaxilla of a second adult $\mathrm{T}$. kansasensis $5 p$. nov. (FHSM VP. 13742 ) in dorsal $(D)$, ventral $(E)$, oblique left lateral $(F)$ view. Note that the anterior end of the VP-13742 premaxilla had apparently been removed prior to burial by the bite of a large shark. Scale bars equal $5 \mathrm{~cm}$.
(1990, p. 22) indicated that, 'two tylosaurine species have been found in this horizon, Tylosaurus nepaeolicus and Tylosaurus n. sp.' He also noted (p. 25) that, 'Tylosaurus n. sp. is limited to the zone of Protosphyraena perniciosa' and included the undescribed species in his taxonomic listing without designating any specimens. Stewart's (1990) biostratigraphic zone of Protosphyraena perniciosa is late Coniacian in age and includes Hattin's (1982) marker units (mu) 1 through 5.

Another specimen (FHSM VP-13742) which included a disarticulated skull and limb elements was collected by the author from the lower chalk in 1990. While neither the parietal nor the quadrates were recovered, the medial posterior edge of the frontal is notched in a such a way as to suggest that it had been invaded by the parietal foramen. The anterior extension of the premaxilla is short and rounded, and does not resemble that of $T$. nepaeolicus or $T$. proriger. The upper portion of the anterior end of the premaxilla appears to have been removed by the bite of a large shark (Fig. 8D - F), and the tip of a Cretoxyrhina mantelli tooth is embedded in the dorsal surface of the bone. The broken tip of a Cretoxyrhina tooth is also embedded on the lateral side of each of the dentaries.

Later in 1990, a juvenile Tylosaurus skull and six cervical vertebrae (FHSM VP-15632) were collected by the author from near the same locality and stratigraphic level as VP-13742. The specimen preserves the frontal and parietal, both quadrates, the premaxilla, both maxillae and both lower jaws. The anterior of the premaxilla is shortened and rounded compared to the two other species of Tylosaurus, the parietal foramen opens anteriorly on the suture between the frontal and the parietal, and neither of the well-preserved quadrates exhibits an infrastapedial process (Fig. 3D.1 - D.4). The remains are similar in size and preservation to those of the paratype FHSM VP-2495 (Fig. 5), which were identified as Tylosaurus novum sp. by Bell $(1993,1997)$. The remains of a young Tylosaurus (FHSM VP-14848; estimated $2 \mathrm{~m}$ total length) collected in 1990 from the lower Smoky Hill Chalk is here identified as T. kansasensis sp. nov. on the basis of the lack of a infrastapedial process on the left quadrate.

Bell (1990, pers. comm.) noted that one of the exhibited specimens (FHSM VP-78) at the original Sternberg Museum was mislabelled as Platecarpus and was, instead, the undescribed species of Tylosaurus. In his phylogenetic revision of the Mosasauroidea, Bell (1993, p. 254; 1997, p. 328) included the informal name 'Tylosaurus novum sp.' and identified seven specimens: FHSM VP-78, VP-2295, VP-2495; LACM 127815; MCZ 1589; YPM 3392 (3992) and YPM 40796. YPM 3992 is omitted here because the quadrate belonging to this specimen was originally figured as that of T. nepaeolicus by Russell (1967, fig. 94). The same figure was used by Schumacher (1993, fig. 10) and Bell (1993, fig. 11B; 1997, fig. 7) and identified as T. nepaeolicus. Because Bell noted that the figured quadrate had an infrastapedial process (1993, 1997), the original identification of YPM 3992 by Russell is retained here pending 
further interpretation. Although Bell (1993, pp. 188 - 190) listed thirteen provisional characters (Table 1) from FHSM VP2295 and LACM 127815 in his diagnosis of the undescribed Tylosaurus novum sp., he did not describe the individual specimens.

Schumacher (1993; pers. comm., 2004) noted that the infrastapedial process of the quadrate was greatly reduced or lacking on the quadrates of three specimens (FHSM VP-78, VP2295, and VP-3366) of Tylosaurus sp. in the Sternberg Museum collection, and illustrated the left quadrate of VP-2295 (1993, fig. 12) and the right quadrate of VP-3366 (1993, figs. 13, 28). He (1993) also reported that the rostrum of VP-78 and VP-2295 were 'unusually pointed and rounded' compared to the blunt, cylindrical rostra of Tylosaurus proriger and T. nepaeolicus, and that in VP-78, the parietal foramen invades the suture between the frontal and parietal. The parietal foramen is crushed laterally in VP-2295 but still visible (Fig. 4). Although the rostrum of VP-3366 is also shortened and rounded (Schumacher, 1993, fig. 28), neither the frontal nor the parietal are preserved in the remains.

An articulated, partial skull of a young mosasaur in the Sternberg Collection (VP-9350) is here identified as Tylosaurus kansasensis sp. nov. In addition, an articulated skull and lower jaws of the third species (FGM V-43) (Fig. 9) was collected by G.F. Sternberg and is currently on exhibit in the Fryxell Geology Museum at Augustana College in Rock Island, Illinois. An isolated premaxilla (TMM 40092-27) and an associated premaxilla and right quadrate (TMM 31051-64) in the Texas Memorial Museum collection have similar characteristics to the Kansas specimens but require further study.

Novas et al. (2002) erected a new genus and species of basal tylosaurine, Lakumasaurus antarcticus, from Antarctica. The southern hemisphere material, however, is much younger (late Campanian/Maastrichtian) than T. kansasensis sp. nov. In $L$. antarcticus the 'premaxillary rostrum' is large, the parietal foramen is located 'well behind the frontoparietal suture', but the quadrates as illustrated do not appear to have an infrastapedial process.

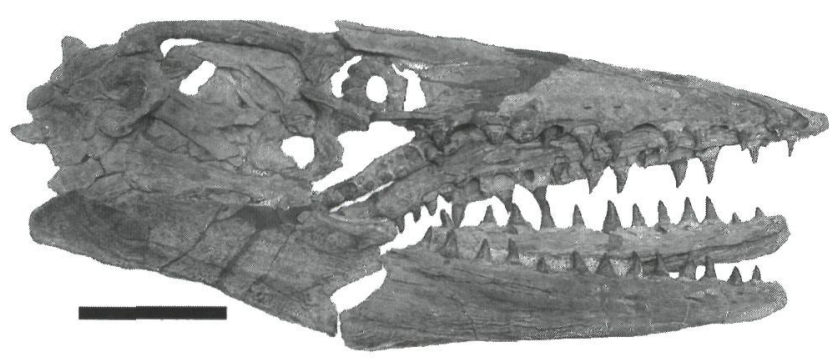

Fig. 9. The skull of an adult Tylosaurus kansasensis sp. nov. (FGM V-43) in ventral-right lateral view, showing the upper and lower jaws, right quadrate and portions of both pterygoids. Some of the teeth were reconstructed by G.F. Sternberg. Scale bar equals $15 \mathrm{~cm}$.
During the course of this study, mosasaur specimens in the collections of the following institutions were examined and no additional remains of Tylosaurus kansasensis sp. nov. were identified: the University of Kansas Museum of Geology, the Denver Museum of Science and Nature, the Geology Museum, South Dakota School of Mines and Technology, the Field Museum, the Cincinnati Museum Center, the Geology Museum at the University of Wisconsin-Madison, the University of Nebraska State Museum, the Academy of Natural Sciences of Philadelphia, and the United States National Museum.

The remains of a basal tylosaurine, Tylosaurus kansasensis nov. sp., have been collected from the lower Smoky Hill Chalk of western Kansas since at least 1876, and thirteen specimens are presently identified in five museum collections. Nine of those specimens, including the holotype and one paratype designated here, are in the collection of the Sternberg Museum of Natural History, Hays, Kansas. While at least four of the individuals appear to be adults, the specimens in total represent a reasonably complete growth series. Recognition of this basal species of tylosaurine mosasaur adds to our knowledge of the rapid evolution and diversity of mosasaurs, and their niche as apex predators within the marine environment of the Late Cretaceous.

\section{Acknowledgements}

The author is indebted to a number of people who have contributed to this study over the years and made this paper possible. I thank J.D. Stewart for our informative discussions regarding the biostratigraphy of the chalk, and for his encouragement of my work. Gorden L. Bell Jr. provided critical information regarding diagnostic characters and specimens, and further explanations of his original work on the third species of Tylosaurus. Richard Zakrzewski (Sternberg Museum of Natural History, Fort Hays State University), Larry Martin and Desui Miao (University of Kansas Museum of Natural History), Mary Ann Turner (Yale Peabody Museum), Charles Schraff (Harvard Museum of Comparative Zoology), Samuel MacLeod (Los Angeles County Museum of Natural History), and Richard Anderson and William Hammer (Fryxell Geology Museum, Augustana College) provided access to and background information regarding specimens in their care. Earl Manning (Tulane University) supplied copies of early publications and valuable discussions regarding the history of palaeontology in Kansas. Takehito Ikejiri (Fort Hays State University) provided photographs of Tylosaurus specimens in the Harvard (MCZ) collection. Duane and Marion Cheney generously allowed access to their property where two of the more recent specimens were collected. Johan Lindgren, Eric Mulder and the editors of this volume provided valuable suggestions regarding an earlier version of this paper. 


\section{References}

Bell, G.L. Jr., 1993. A phylogenetic revision of Mosasauroidea. University of Texas at Austin (Austin): 293 pp. (unpubl. PhD thesis).

Bell, G.L. Jr., 1997. A phylogenetic revision of North American and Adriatic Mosasauroidea. In: Callaway, J.M. \& Nicholls, E.L. (eds): Ancient marine reptiles. Academic Press (San Diego): 293-332.

Cope, E.D., 1869. (Remarks on Macrosaurus proriger). Proceedings of the Academy of Natural Sciences of Philadelphia 11(81): 123.

Cope, E.D., 1870. Synopsis of the extinct Batrachia and Reptilia of North America. Transactions of the American Philosophical Society n.s. 14: 1-252 + i-viii.

Cope, E.D., 1872. (Remarks on discoveries recently made by Prof. 0. C. Marsh). Proceedings of the Academy of Natural Sciences of Philadelphia 24: 140-141.

Cope, E.D., 1874. Review of the Vertebrata of the Cretaceous period found west of the Mississippi River. United States Geological Survey of the Territories, Bulletin 1(2): 3-48.

Cope, E.D., 1875. The Vertebrata of the Cretaceous formations of the West. Report of the United States Geological Survey of the Territories (Hayden) 2: $302 \mathrm{pp}$.

Everhart, M.J., 2001. Revisions to the biostratigraphy of the Mosasauridae (Squamata) in the Smoky Hill Chalk Member of the Niobrara Chalk (Late Cretaceous) of Kansas. Transactions of the Kansas Academy of Science 104: 56-75.

Everhart, M.J., 2002. New data on cranial measurements and body length of the mosasaur, Tylosaurus nepaeolicus (Squamata; Mosasauridae), from the Niobrara Formation of western Kansas. Transactions of the Kansas Academy of Science 105: 33-43.

Everhart, M.J., 2004. Late Cretaceous interaction between predators and prey. Evidence of feeding by two species of shark on a mosasaur. PalArch 1: 1-7.

Everhart, M.J. \& Everhart, P.A., 1997. Earliest occurrence of the mosasaur, Tylosaurus proriger (Mosasauridae: Squamata) in the Smoky Hill Chalk (Niobrara Formation, Upper Cretaceous) of western Kansas. Journal of Vertebrate Paleontology 17 (Suppl. to 3): 44A.

Hattin, D.E., 1982. Stratigraphy and depositional environment of the Smoky Hill Chalk Member, Niobrara Chalk (Upper Cretaceous) of the type area, western Kansas. Kansas Geological Survey, Bulletin 225: 1-108.

Leidy, J., 1873. Contributions to the extinct vertebrate fauna of the western interior territories. Report of the United States Geological Survey of the Territories (Hayden) 1: $358 \mathrm{pp}$.

Marsh, O.C., 1872a. On the structure of the skull and limbs in mosasaurid reptiles, with descriptions of new genera and species. American Journal of Science 3(18): 448-464.

Marsh, O.C., 1872b. Note on Rhinosaurus. American Journal of Science 4(20): 147.

Merriam, J.C., 1894. Ueber die Pythonomorphen der Kansas-kreide. Palaeontographica 41: 1-39.

Novas, F.E., Fernández, M., Gasparini, Z.B., Lirio, J.M., Nuñez, H.J. \&

Puerta, P., 2002. Lakumasaurus antarcticus, n. gen. et sp., a new mosasaur (Reptilia, Squamata) from the Upper Cretaceous of Antarctica. Ameghiniana 39: 245-249.

Russell, D.A., 1967. Systematics and morphology of American mosasaurs (Reptilia, Sauria). Bulletin of the Peabody Museum of Natural History, Yale University 23: 1-241.
Schumacher, B.A., 1993. Biostratigraphy of Mosasauridae (Squamata, Varanoidea) from the Smoky Hill Chalk Member, Niobrara Chalk (Upper Cretaceous) of western Kansas. Fort Hays State University (Hays, Kansas): 68 pp. (unpubl. MSc thesis).

Sheldon, M.A., 1996. Stratigraphic distribution of mosasaurs in the Niobrara Formation of Kansas. Paludicola 1: 21-31.

Stewart, J.D., 1990. Niobrara Formation vertebrate stratigraphy. In: Bennett, S.C. (ed.): Niobrara Chalk Excursion Guidebook. University of Kansas Museum of Natural History and Kansas Geological Survey: 19-30.

Williston, S.W., 1898. Mosasaurs. University Geological Survey of Kansas 4: 83-221. 


\section{Appendix 1}

Holotype - FHSM VP-2295, a complete, articulated skull with seven cervical vertebrae (Fig. 2). The skull was collected by M.V. Walker in November 1968 from the lower Smoky Hill Chalk of Ellis County, eight miles northeast of the town of Ellis. It was originally identified by Bell in 1990 as Tylosaurus nepaeolicus and later re-identified by Bell (1993) as Tylosaurus novum sp. The lower jaw length measures $72 \mathrm{~cm}$ (28 in.) and represents a 5-m (16 ft) adult. Diagnostic characters of FHSM VP-2295 (as Tylosaurus novum sp.) were used by Bell (1993, 1997 ) in the cladistic analysis supporting his phylogenic revision of the Mosasauroidea. The skull exhibits several unhealed, deep gouges (tooth marks) on the frontal and the right dentary (see also Schumacher, 1993, fig. 27). It is currently on exhibit in the Sternberg Museum of Natural History, Hays, Kansas.

Other referred specimens - LACMNH 127815 (paratype), a complete skull, vertebrae and limb elements, discovered at locality LACM 5539, SW of Plainville in Rooks County, in the lower Smoky Hill Chalk. The accession and catalogue entry for the specimen indicate it was collected 8 July 1966 by J.D. Stewart (McLeod, pers. comm., 2004). It was identified by Bell (1993) as Tylosaurus novum sp. Bell (pers. comm., 2005) noted that the parietal foramen is located $5.5 \mathrm{~mm}$ behind the frontal-parietal suture, the quadrates lack an infrastapedial process, the premaxilla is rounded in lateral profile and the dentary is about $41 \mathrm{~cm}$ in length. This specimen is almost identical in size to the holotype.

FHSM VP-2495 (paratype), a disarticulated, near-complete skull (missing the premaxilla) of a juvenile Tylosaurus and the anteriormost portion of the vertebral column ( 83 vertebrae). There was no limb material associated with the specimen. This is a common condition for the remains of many mosasaurs collected from the chalk and is most likely the result of scavenging by sharks. The remains were collected by $R$. Zakrzewski in November 1969 from the lower Smoky Hill Chalk of Trego County. The length of the left lower jaw is $50 \mathrm{~cm}$, and represents an individual that would have been about $3.6 \mathrm{~m}$ long.

FHSM VP-78, a nearly complete skull and four vertebrae mounted in plaster in a dorsal-right lateral view. The remains were collected by G.F. Sternberg in March 1938 from the lower Smoky Hill Chalk of Gove County. Portions of the left squamosal, parietal, right prefrontal, right maxilla and right articular have been restored. The lower right jaw measures 44 $\mathrm{cm}$. Although a damaged right quadrate is stored in the collection, the left quadrate was set in its place in the plaster mounting (Schumacher, 1993, fig. 25). VP-78 was originally identified as Platecarpus by Sternberg. The specimen was reidentified by Russell (1967) as Tylosaurus nepaeolicus.
FHSM VP-3366, an unmounted, partial skull (including premaxilla and a right quadrate) with twenty-four cervical and dorsal vertebrae, rib fragments (one with a healed fracture), and preserved thoracic cartilage. Scavenging by Squalicorax falcatus is indicated by serrated bite marks on the remains. Collected by R.L. Bliss in April 1972 from the lower Smoky Hill Chalk of Gove County.

FHSM VP-9350, the unmounted, partial skull (including the premaxilla, left maxilla, left quadrate and both lower jaws) of a juvenile Tylosaurus that was discovered lying on its right side on the surface of the chalk. The specimen was weathered when found and preservation is poor. Lower jaw length is 37 $\mathrm{cm}$ and the height of the left quadrate is $3.6 \mathrm{~cm}$. The remains were collected by H.E. LaGarry in September 1987 from the lower chalk of Graham County and originally identified as Platecarpus.

FHSM VP-13742, the weathered and fragmentary skull of an adult Tylosaurus including the premaxilla, portions of both maxillae, a complete frontal and both lower jaws (lacking both quadrates), and a few bones from the front limbs. The remains were discovered by the author in February 1990 on the surface of the low chalk (between mu4 and mu5) of Gove County. The tips of three shark teeth (Cretoxyrhina mantelli) were embedded in the top of the premaxilla and the lateral side of both dentaries. In addition, the anterior end of the premaxilla had apparently been sheared off by the bite of a shark and the damaged bone shows no evidence of healing. The lower jaws measure $98 \mathrm{~cm}$, suggesting a mosasaur of about $7 \mathrm{~m}$ in total length (Everhart, 2002). VP-13742 is the largest known example of Tylosaurus kansasensis sp. nov.

FHSM VP-14848, forty-eight cervical, dorsal and caudal vertebrae and fragments of the skull, including the parietal, braincase and left quadrate, of a small $(2 \mathrm{~m})$ Tylosaurus kansasensis sp. nov. The specimen was collected in 1990 from the lower chalk of Gove County by P.A. Everhart. The left quadrate (about $3.7 \mathrm{~cm}$ in height) is broken at mid-shaft but complete. No limb material is present.

FHSM VP-15631, the complete skull (including premaxilla, frontal/parietal and partial right quadrate), pectoral girdle and most of both front limbs, several ribs and a series of fortytwo consecutive cervical, dorsal and caudal vertebrae of an adult Tylosaurus. The specimen was collected by the author in November 1979 from the lower chalk (mu1-mu2) of Ellis County. The overall condition is poor due to plant roots and subsurface weathering.

FHSM VP-15632, a fragmentary skull of a juvenile Tylosaurus (including the premaxilla, frontal/parietal, both quadrates and both lower jaws) and five cervical vertebrae. The left lower jaw measures $42 \mathrm{~cm}$. The specimen was discovered by P.A. Everhart in June 1990 in the lower chalk (between mu4 and mu5) of Gove County. A portion of the remains were exposed on the surface and some bones were damaged by weathering and plant roots. 
FGM V-43, a complete, articulated skull (including the right quadrate, premaxilla, right sclerotic ring and both lower jaws) and two cervical vertebrae, mounted in ventral right-lateral view (Fig. 9) in the collection of the Fryxell Museum of Geology, Augustana College, Rock Island, Illinois. The frontalparietal suture is obscured by the plaster mounting. The right lower jaw measures $82.5 \mathrm{~cm}$. The specimen was collected by G.F. Sternberg and later acquired by Augustana College. There is no record of the locality or stratigraphic occurrence. G.F. Sternberg's correspondence in the files of the Fryxell Museum mentions a similar skull (\#10437) found in Trego County (lower chalk).

MCZ 1589, fragments of the skull of an adult T. kansasensis sp. nov. including the premaxilla, left maxilla, right dentary and left quadrate in the collection of the Museum of Comparative Zoology (MCZ), Harvard University (Cambridge, MA). The specimen was collected by C.H. Sternberg from the Smoky Hill Chalk of Logan County and acquired by the MCZ in 1894 (per telecom with Charles Schaff, MCZ, 8/16/2004). There is no record of the locality or stratigraphic occurrence. The specimen was originally identified as Tylosaurus dyspelor, and was reidentified as Tylosaurus novum sp. by Bell (1993). The right dentary is about $46 \mathrm{~cm}$ in length, suggesting a lower jaw length of about $81 \mathrm{~cm}$.

YPM 40796, fragmentary remains, including the parietal and a quadrate, but no premaxilla, collected by B.F. Mudge from Graham County in September 1876. The specimen was originally identified as Tylosaurus sp., and was reidentified as Tylosaurus novum sp. by Bell (1993). The dentary is about $24 \mathrm{~cm}$ in length (Bell, pers. comm., 2005), suggesting a lower jaw length of about $43 \mathrm{~cm}$. 